\title{
Temporal and Region-Specific Requirements of $\alpha$ CaMKII in Spatial and Contextual Learning
}

\author{
Katharina G. Achterberg, ${ }^{1}$ Gabriëlle H.S. Buitendijk, ${ }^{2}$ Martijn J. Kool, ${ }^{2,3}$ Susanna M.I. Goorden, ${ }^{2,3}$ Laura Post, ${ }^{2}$ \\ Denise E. Slump, ${ }^{1}$ Alcino J. Silva, ${ }^{4}$ Geeske M. van Woerden, ${ }^{2,3}$ Steven A. Kushner, ${ }^{1}$ and Ype Elgersma ${ }^{2,3}$ \\ ${ }^{1}$ Department of Psychiatry, ${ }^{2}$ Department of Neuroscience, and ${ }^{3}$ ENCORE Expertise Center for Neurodevelopmental Disorders, Erasmus University Medical \\ Center, 3015 GE, Rotterdam, The Netherlands, and ${ }^{4}$ Departments of Neurobiology, Psychiatry, Psychology, and Brain Research Institute, University of \\ California, Los Angeles, California 90095
}

The $\alpha$ isoform of the calcium/calmodulin-dependent protein kinase II ( $\alpha$ CaMKII) has been implicated extensively in molecular and cellular mechanisms underlying spatial and contextual learning in a wide variety of species. Germline deletion of Camk2a leads to severe deficits in spatial and contextual learning in mice. However, the temporal and region-specific requirements for $\alpha$ CaMKII have remained largely unexplored. Here, we generated conditional Camk2a mutants to examine the influence of spatially restricted and temporally controlled expression of $\alpha$ CaMKII. Forebrain-specific deletion of the Camk2a gene resulted in severe deficits in water maze and contextual fear learning, whereas mice with deletion restricted to the cerebellum learned normally. Furthermore, we found that temporally controlled deletion of the Camk2a gene in adult mice is as detrimental as germline deletion for learning and synaptic plasticity. Together, we confirm the requirement for $\alpha$ CaMKII in the forebrain, but not the cerebellum, in spatial and contextual learning. Moreover, we highlight the absolute requirement for intact $\alpha$ CaMKII expression at the time of learning.

Key words: CaMKII; cerebellum; fear conditioning; hippocampus; learning; spatial learning

\section{Introduction}

Mouse genetic studies using targeted mutations of the Camk2a gene have greatly contributed to establishing the causal link between synaptic plasticity and learning (Silva et al., 1992a; Silva et al., 1992b; Giese et al., 1998; Elgersma et al., 2002). However, the interpretation of results using germline knock-out mice requires consideration of possible neurodevelopmental influences on the phenotype of adult mice given the absence of gene expression, not only at the time of learning, but also throughout neural development. Perhaps most importantly for interpreting the extensive literature using germline Camk2a knock-out mice, it remains unclear how the absence of the $\alpha$ isoform of the calcium/ calmodulin-dependent protein kinase II ( $\alpha$ CaMKII) during the early postnatal period might adversely influence brain development, thereby leading to the observed deficits in spatial and contextual learning. In contrast, most current models of $\alpha$ CaMKII function in synaptic plasticity and learning posit its requirement

\footnotetext{
Received Feb. 14, 2014; revised April 1, 2014; accepted April 3, 2014.

Author contributions: A.J.S., S.A.K., and Y.E. designed research; K.G.A., G.H.S.B., M.J.K., L.P., D.E.S., G.M.v.W., and Y.E. performed research; K.G.A., G.H.S.B., M.J.K., S.M.I.G., S.A.K., and Y.E. analyzed data; K.G.A., G.H.S.B., M.J.K., S.M.I.G., G.M.v.W., S.A.K., and Y.E. wrote the paper.

This work was supported by the Netherlands Organization for Scientific Research (ALW-Veni project to Geeske M. van Woerden, a ZonMw-Vidi project to Steven A. Kushner, and a ZonMw-Vici project to Ype Elgersma), the NeuroBasic-PharmaPhenomics consortium, the Dutch Technology Foundation STW (Steven A. Kushner, Ype Elgersma) and FP7 EU Marie Curie (Grant 254711 to Steven A. Kushner). We thank Erika Goedknegt, Minetta Elgersma, and Mehrnoush Aghadavoud Jolfaei for technical support.

The authors declare no competing financial interests.

Correspondence should be addressed to either Steven A. Kushner or Ype Elgersma, Dr. Molewaterplein 50, Ee1493, 3015 GE Rotterdam, The Netherlands, E-mail: s.kushner@erasmusmc.nl or y.elgersma@erasmusmc.nl.

DOI:10.1523/JNEUROSCI.0640-14.2014

Copyright $\odot 2014$ the authors $\quad 0270-6474 / 14 / 3411180-08 \$ 15.00 / 0$
}

at the time of learning independently of any developmental influences (for review, see Elgersma et al., 2004). Therefore, distinguishing between the potential developmental influences of $\alpha \mathrm{CaMKII}$ and its necessity at the time of learning remains a highly important goal.

Many distinct brain regions have robust $\alpha$ CaMKII expression, for which germline Camk2a knock-out mice have not provided a definitive experimental model to dissociate region-specific influences. In the cortex and hippocampus, $\alpha$ CaMKII is exclusively found in glutamatergic pyramidal neurons (Benson et al., 1992; Jones et al., 1994; Sik et al., 1998), whereas, in the striatum, it is localized to GABAergic medium-spiny neurons (Benson et al., 1992; Takeuchi et al., 2002). In addition, $\alpha$ CaMKII is expressed in cerebellar Purkinje cells, where it is required for intact parallel fiber-Purkinje cell long-term depression (LTD) (Hansel et al., 2006), a form of plasticity suggested to contribute not only to motor learning, but also to spatial and contextual learning (Lalonde and Strazielle, 2003; Burguière et al., 2005; Goddyn et al., 2006; Burguière et al., 2010; Galliano et al., 2013). Therefore, examining the region-specific role of $\alpha$ CaMKII on learning offers unique insights into the functioning of this highly abundant synaptic protein and, more generally, on the systems-level neurobiology of spatial memory.

In the present study, we engineered a conditional Camk2a allele to fully parameterize the contribution of $\alpha$ CaMKII to learning and memory, thereby permitting spatiotemporal control over deletion. We found that loss of $\alpha$ CaMKII in adulthood leads to similar deficits as observed in the global knock-out, which lacks $\alpha$ CaMKII expression from conception. Moreover, we confirm the critical importance of $\alpha$ CaMKII in the cortex and hippocam- 
A

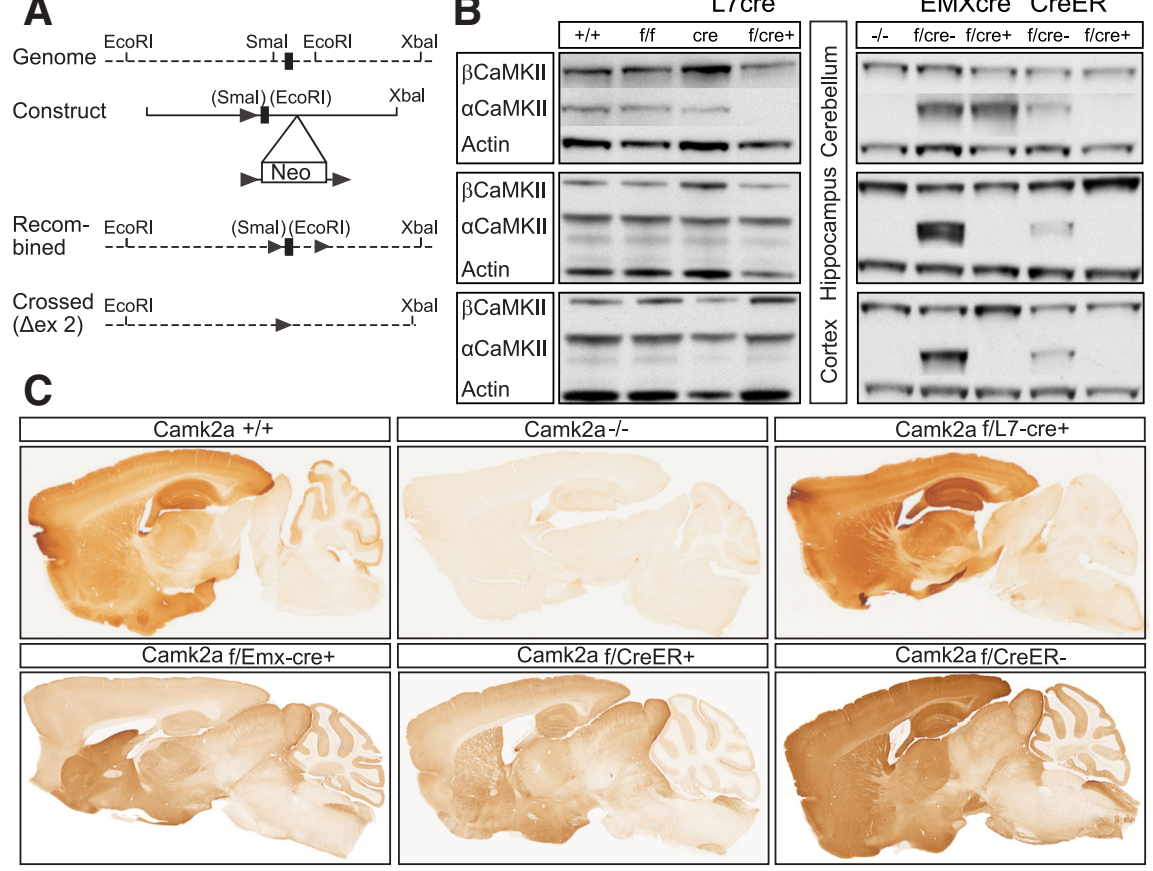

Figure 1. Generation of spatial and temporal specific Camk2a knock-out mice. A, Schematic diagram for the generation of floxed Camk2a knock-out mice (Genome) Wild-type Camk2a locus with exon 2 depicted as a black box. (Construct) Targeting construct used for introducing the LoxP sites and neomycin resistance (Ne0) gene in the Camk2a locus. The LoxP sites flanking exon 2 and the Neo gene are depicted as triangles. (Recombined) Mutant Camk2a flox locus after homologous recombination and Cre recombination in ES cells and consequential deletion of the Neo gene; (Crossed), The mutant Camk2a knock-out locus after crossing with Cre-positive mice and subsequent deletion of exon 2 in targeted cells. $\boldsymbol{B}$. Western blots using antibodies for $\alpha$ CaMKII, $\beta$ CaMKII, and actin demonstrate that: (1) the $\alpha$ CaMKII level is specifically decreased in the cerebellum of Camk2a flox/L7-cre+ mice, but not in cortex or hippocampus (left); (2) the $\alpha$ CaMKII level is specifically decreased in the cortex and hippocampus of Camk2a flox/Emx-cre+ mice, but not in the cerebellum (middle); and (3) $\alpha$ CaMKII level is decreased in all structures of Camk2 $a^{\text {flox/CreER+ }}$ mice (right). For all genotypes, Cre-negative mice are unaffected in their $\alpha$ CaMKII and $\beta$ CaMKII expression levels. C, $\alpha$ CaMKII stainings showing: (1) normal staining in Camk $2 a^{+/+}$mice (top left); (2) no staining in Camk2a- $2 a^{-}$mice (top middle); (3) specific $\alpha$ CaMKII deletion in Purkinje cells in Camk2a flox/l7 - cre + mice (top right); (4) specific $\alpha$ CaMKII deletion in forebrain, but not cerebellar cells in Camk2 $a^{\text {flox/Emx-cre+ }}{ }^{\text {mice (bottom }}$ left); (5) specific $\alpha$ CaMKII deletion throughout the brain in Camk2 $a^{\text {flox/CreeR+ }}$ mice (bottom middle); and (6) normal staining in Camk2a flox/CreER - mice (bottom right).

pus for intact spatial and contextual learning, but found that its expression in the cerebellum is dispensable. Together, the results of the present study show that, in contrast to cerebellar $\alpha$ CaMKII, the loss of forebrain $\alpha$ CaMKII has severe adverse effects on spatial learning in mice. Furthermore, deletion of Camk2a in adulthood is sufficient to fully recapitulate the learning impairments of global knock-out mice. This finding confirms the critical necessity of forebrain $\alpha$ CaMKII expression at the time of learning.

\section{Materials and Methods}

Animals. The following mice were used in this study: Camk2a ${ }^{+/+}(\mathrm{WT})$; Camk2a flox (homozygously floxed Camk2a mice); Camk2a flox/L7 -cre and Camk2a flox/L7-cre+ (Purkinje cell-specific $\alpha$ CaMKII knock-out mice); Camk $2 a^{\text {flox/Emx -cre }-}$ and Camk2a flox/Emx-cre+ (telencephalon-restricted $\alpha$ CaMKII knock-out mice); Camk2a flox/CreER - and Camk $2 a^{\text {flox/CreER+ }}$ (global $\alpha$ CaMKII knock-out mice with temporal control over gene deletion); and germline $\alpha$ CaMKII knock-out mice $\left(\operatorname{Camk} 2 a^{-1-}\right)$. All mice were backcrossed $>10$ times into the C57BL/6JOlaHsd background.

Mice were group housed and maintained under a $12 \mathrm{~h} \mathrm{light/dark} \mathrm{cycle}$ (lights on at 07:00 A.M.), with ad libitum access to food and water. Behavioral testing was performed during the light phase. The experimenter remained blinded to the genotype throughout the experiments and data analysis. All behavioral experiments were performed using littermates. Mice were between 2 and 5 months of age. Experimental group assignments were made in consideration of sex and age matching. All experiments were performed in accordance with the Dutch Animal Ethical Committee (DEC).

Generation of floxed Camk2a mice. Camk2a floxed mutant ES cells were generated as follows: a genomic clone of $\sim 8 \mathrm{~kb}$ encoding the Camk2a exon 2 (aa 22-53) was isolated by screening a mouse library. The targeting construct was made by inserting a PGK neomycin cassette flanked by LoxP sites into the EcoRI site $\sim 1.2 \mathrm{kbp}$ downstream of exon 2 . Another LoxP site was inserted into the SmaI site $60 \mathrm{bp}$ upstream of exon 2. Targeted ES clones (61 of 130) were identified by Southern blot analysis. PCR analysis revealed that 20 of these 61 clones contained the additional 5' LoxP site. The PGK neocassette was removed by transient expression of Cre recombinase (pBS185; Invitrogen). Therefore, a mutant allele was created in which the Camk2a exon 2 was flanked by LoxP sites (Fig. 1A).

Generation of L7-cre mice. Heterozygous floxed $\alpha$ CaMKII mice were crossed with L7/ pcp-2 Cre transgenic mice (RRID:IMSR_JAX:004146; Oberdick et al., 1990; Barski et al., 2000). Male Camk2a $a^{\text {flox/L7-cre+ }}$ mice from this $\mathrm{F} 1$ offspring were crossed with $\mathrm{fe}$ male Camk $2 a^{\text {flox/L7 }- \text { cre }-~ m i c e ~ t o ~ o b t a i n ~ t h e ~}$ two experimental genotypes investigated: Camk2a flox/L7-cre - and Camk2a flox/L7-cre+ L7 is expressed in cerebellar Purkinje cells in utero. Therefore, in Camk $2 a^{\text {flox/L7-cre }+}$ mice, deletion of Camk2a is Purkinje-cell specific and occurs before the normal postnatal expression of $\alpha$ CaMKII (Smeyne et al., 1991).

Generation of Emx1-cre mice. Camk2a flox mice were crossed with Emx1-Cre transgenic mice (RRID:IMSR_RBRC01345; Iwasato et al., 2004). Male Camk $2 a^{\text {flox/Emx }- \text { cre+ }}$ mice from this F1 offspring were crossed with female Camk2 $a^{\text {flox }}$ mice. Male Camk2a $a^{\text {flox/Emx-cre+ }}$ mice from this F2 offspring were crossed again with female Camk2a flox to obtain the two experimental genotypes: $\operatorname{Camk} 2 a^{\text {flox/Emx-cre }-}$ and $\operatorname{Camk} 2 a^{\text {flox/Emx-cre }+}$. Emxl is expressed in glutamatergic telencephalic neurons in utero (Simeone et al., 1992). Therefore, in Camk2a flox/Emx-cre+ mice, deletion of Camk2a is restricted to the telencephalon and occurs before the normal postnatal expression of $\alpha$ CaMKII.

Generation of Cre $e^{\mathrm{ER}}$ mice. $\mathrm{Cre} \mathrm{ER}^{\mathrm{ER}}$ mice were generated by engineering a fusion protein between cre recombinase and the ligand binding domain of a tamoxifen-responsive mutant human estrogen receptor, driven by the widespread CMV early enhancer/chicken $\beta$ actin (CAG) promoter (RRID:IMSR_JAX:004682; Hayashi and McMahon, 2002). Only upon tamoxifen binding will the Cre ${ }^{\mathrm{ER}}$ protein translocate into the nucleus and catalyze loxP recombination (Van Duyne, 2001). Therefore, tamoxifen administration in adulthood allows the normal endogenous expression of $\alpha$ CaMKII protein throughout development. For breeding of the experimental genotypes, male $\mathrm{Cr} e^{\mathrm{ER}+}$ mice were crossed with female Camk $2 a^{\text {flox }}$ mice. The resulting F2 male Camk $2 a^{\text {flox/CreER }+}$ mice were crossed with female Camk $2 a^{\text {flox }}$ mice to obtain the Camk2a flox/CreER+ and Camk $2 a^{\text {flox/CreER - }}$ genotypes.

Tamoxifen injections for Cre ${ }^{\mathrm{ER}}$ experiments. Adult deletion of Camk2a was achieved using four injections of tamoxifen. Tamoxifen (SigmaAldrich) was dissolved in sunflower oil in a dilution of $20 \mathrm{mg} / \mathrm{ml}$. Injections were performed once daily for 4 consecutive days at a dose of 0.10 $\mathrm{mg} / \mathrm{g}$ bodyweight. Behavioral testing was initiated 4 weeks after the first day of tamoxifen injection (Hayashi and McMahon, 2002). Importantly, to control for any potential influence of tamoxifen itself, all mice (both 
$\operatorname{Camk} 2 a^{\text {flox/CreER+ }}$ and $\operatorname{Cam} k 2 a^{\text {flox/CreER - }}$ ) received tamoxifen injections. Notably, however, previous studies have demonstrated that, using this dosing regimen, the administration of tamoxifen has no discernible influence on emotional reactivity, neurological functioning, or learning (Vogt et al., 2008).

Morris water maze. All mice were handled for $1 \mathrm{~min}$ daily beginning a week before the experiment. The water maze is a circular pool with a diameter of $1.2 \mathrm{~m}$ that is filled with an opaque mixture of water and white paint. Water temperature was maintained at $25-26^{\circ} \mathrm{C}$. The escape platform had a diameter of $11 \mathrm{~cm}$ and was submerged $1 \mathrm{~cm}$ beneath the water surface. The swimming paths of the animals were captured by a closedcircuit video camera mounted directly above the center of the pool and analyzed using Smart version 2.0 software (Panlab rib_00052). The room was illuminated by ceiling lamps set to a low level of light intensity. Visually salient and readily distinguishable distal cues were displayed on each wall of the room.

Mice were trained using two $60 \mathrm{~s}$ trials per day, with a $30 \mathrm{~s}$ intertrial interval, for 5 consecutive days. During training, mice were placed on the platform for $30 \mathrm{~s}$ and subsequently placed into the pool at pseudorandom starting positions. After reaching the platform, the mice were allowed to remain for $30 \mathrm{~s}$ before returning to their home cage. If a mouse was unable to locate the platform within $60 \mathrm{~s}$, the trial was concluded and the mouse was gently placed on the platform by the experimenter and remained there for $30 \mathrm{~s}$. The platform location was in a fixed position throughout all trials. For each trial, latency, distance covered, mean swim speed, and path were measured.

On day 5, a probe trial was performed $1 \mathrm{~h}$ after the training, in which the platform was removed to assess spatial learning. During the probe trial, mice were placed in the pool at the opposite side of the platform position and were allowed to search for $60 \mathrm{~s}$. The amount of time spent in each quadrant and platform location crossings were measured for each probe trial. For statistical analysis, the time in the target quadrant was compared with the average of the other three quadrants.

Pavlovian fear conditioning. Mice were placed in a steel chamber $(30 \times$ $20 \mathrm{~cm}$ ) with a grid floor and a clear plastic door and ceiling (Med Associates). On day 1 , each mouse was placed inside the conditioning chamber for $180 \mathrm{~s}$. A single foot shock (2 s, $0.4 \mathrm{~mA})$ was delivered after a placement-to-shock interval of $148 \mathrm{~s}$. Twenty-four hours later, mice were returned to the same context for $180 \mathrm{~s}$. Behavior during training and testing was recorded using a closed-circuit video camera mounted directly in front of the chambers. Freezing behavior, defined as the cessation of all movement except respiration, was quantified using an automated video-based algorithm with detection parameters calibrated by independent manual scoring (Anagnostaras et al., 2010).

Western blots. Mice were anesthetized with isoflurane and decapitated. Cortex, hippocampus, and cerebellum were rapidly dissected and frozen in liquid nitrogen. Tissue samples were homogenized using a Dounce homogenizer in lysis buffer $(0.1 \mathrm{M}$ Tris- $\mathrm{HCl}, \mathrm{pH} 6.8,4 \%$ SDS) containing protease and phosphatase inhibitor mixtures (Sigma-Aldrich). Protein concentrations were determined using the BCA method (Pierce) and adjusted to $1 \mathrm{mg} / \mathrm{ml} ; 10 \mu \mathrm{g}$ of protein was loaded per lane. The following antibodies were used: $\alpha$ CaMKII ( 1 : 10,000, catalog \#MAB8699 RRID:AB_2067919; Millipore), $\beta$ CaMKII (1:10,000, catalog \#ab34703 RRID:AB_2275072; Abcam), and actin (1:20,000, catalog \#MAB1501R RRID:AB_94235, Millipore). Samples were electrophoresed using 10\% Bis-Tris gels (Bio-Rad) and blotted on nitrocellulose membranes (Bio-Rad). The membranes were blocked with 5\% nonfat dry milk in TBS with $0.1 \%$ Tween 20 (TBST). Blots were incubated in primary antibody, diluted in TBST with 2\% dry milk, and incubated in secondary antibody (goat anti-mouse, 1:3,000, AffiniPure, catalog \#115-007-003 RRID:AB_2307348, Jackson ImmunoResearch. The blots were incubated in enhanced chemiluminescence reagent (Pierce) exposed to film, and analyzed with Image J version 64 software.

Immunohistochemistry. Mice were deeply anesthetized with pentobarbital and perfused transcardially with a series of PBS, followed by freshly prepared 4\% paraformaldehyde (PFA; Sigma). Brains were carefully removed and fixed for $2 \mathrm{~h}$ in $4 \% \mathrm{PFA}$, followed by $24 \mathrm{~h}$ incubation in $0.1 \mathrm{M}$ phosphate buffer (PB) and 10\% sucrose. Brains were then embedded in gelatin blocks ( $10 \%$ gelatin, $10 \%$ sucrose), postfixed in $10 \%$ formaldehyde and $30 \%$ sucrose for $3 \mathrm{~h}$, and kept in $30 \%$ sucrose overnight at $4^{\circ} \mathrm{C}$. The embedded brains were sectioned using a freezing microtome with a section thickness of $40 \mu \mathrm{m}$. Sections were processed free floating with diaminobenzidine $(0.05 \%)$ as the chromogen.

Slices were rinsed, blocked in $3 \% \mathrm{H}_{2} \mathrm{O}_{2}$ and PBS, rinsed again, and kept at $80^{\circ} \mathrm{C}$ in $10 \mathrm{~mm}$ sodium citrate for $20 \mathrm{~min}$. After rinsing, slices were preincubated for $1 \mathrm{~h}$ at room temperature in 10\% normal horse serum (NHS), $0.5 \%$ Triton X-100, and PBS, and kept overnight at $4^{\circ} \mathrm{C}$ in $10 \%$ NHS, $0.5 \%$ Triton X-100, PBS, and AffiniPure Fab Fragment (donkey anti mouse, 1:200, catalog \#rid_000053, Jackson ImmunoResearch). Subsequently, sections were kept in 10\% NHS, 0.5\% Triton X-100, PBS, and primary antibody ( $\alpha$ CaMKII, 1:9,000, catalog \#MAB8699 RRID: AB_2067919, Millipore) for $48 \mathrm{~h}$ at $4^{\circ} \mathrm{C}$. After rinsing, sections were kept for $2 \mathrm{~h}$ at room temperature in the secondary antibody (RAM-HRP, 1:200, catalog \#P026002 RRID:AB_2307349, Dako) in 10\% NHS, 0.5\% Triton X-100, and PBS. Finally, slices were stained in $0.05 \mathrm{M} \mathrm{PB}, 0.05 \%$ diaminotenzidinetetrachloride, and $3 \% \mathrm{H}_{2} \mathrm{O}_{2}$ for $2 \mathrm{~min}$. Slices were then mounted on slides with chrome (III) potassium sulfate-dodecahydrate, dehydrated in alcohol $(70 \%, 90 \%, 100 \%)$, cleared with xylene, and coverslipped with Permount (Fisher Scientific).

Electrophysiology. Adult mice (15-20 weeks old) were anesthetized with isoflurane and decapitated, after which the brain was taken out quickly and submerged in ice-cold oxygenated (95\%) and carbonated $(5 \%)$ artificial CSF (ACSF; $<4.0^{\circ} \mathrm{C}$ ) containing the following (in $\mathrm{mm}$ ): $120 \mathrm{NaCl}, 3.5 \mathrm{KCl}, 2.5 \mathrm{CaCl}_{2}, 1.3 \mathrm{MgSO}_{4}, 1.25 \mathrm{NaH}_{2} \mathrm{PO}_{4}, 26 \mathrm{NaHCO}_{3}$, and $10 \mathrm{D}$-glucose. Using a vibratome, 400- $\mu \mathrm{m}$-thick sagittal slices were made and then hippocampi were dissected out. Hippocampal slices were allowed to recover in a bath of oxygenated and carbonated ACSF at room temperature for $1.5 \mathrm{~h}$. At onset of the experiment, slices were placed submerged in a recording chamber that was continuously perfused at a rate of $2 \mathrm{ml} / \mathrm{min}$ with oxygenated and carbonated $30^{\circ} \mathrm{C}$ ACSF. All slices were recorded with platinum $(\mathrm{Pt})$ /iridium (Ir) electrodes. Bipolar $\mathrm{Pt} / \mathrm{Ir}$ stimulating electrodes were used to stimulate the slice with a stimulus duration of $100 \mu \mathrm{s}$. Stimulating and recording electrodes were placed on the CA3-CA1 Schaffer-collateral afferents and the dendrites of CA1 pyramidal cells in the stratum radiatum $(150-200 \mu \mathrm{m}$ from stratum pyramidale), respectively. Upon placement of electrodes, slices were given 30 min to rest before onset of measurements. All paired-pulse facilitation (PPF) experiments were done at one-third of slice maximum. Long-term potentiation (LTP) induced using $100 \mathrm{~Hz}$ tetanization ( 1 train of $1 \mathrm{~s}$ at $100 \mathrm{~Hz}$ ) was also evoked at one-third of slice maximum. Theta burst LTP (four trains of four stimuli at $100 \mathrm{~Hz}, 200 \mathrm{~ms}$ apart) were evoked at two-thirds of slice maximum. Unstable recordings were excluded and determinations were made blind to genotype. The magnitude of LTP was defined as the average of the last 10 measurements of the normalized fEPSP slope.

Data analysis and statistics. Hypothesis testing was performed using SPSS version 17 software, as indicated in the "Results" section. Outcomes are expressed as mean \pm SE. Pairwise comparisons were performed using either ANOVA with Tukey's post hoc test or two-tailed $t$ tests, depending upon the experimental design and as specified in the text. Group sizes for each experiment are provided in the figure legends.

\section{Results}

\section{Spatiotemporal deletion of $\alpha$ CaMKII}

To investigate the temporal and region-specific contribution of $\alpha$ CaMKII to the learning deficits observed in global Camk $2 a^{-1-}$ mice, we first generated a floxed allele of Camk2a to enable experiments using spatiotemporally controlled deletion of $\alpha$ CaMKII (Fig. 1A). For each of the cre lines used: L7-cre (cerebellar Purkinje neurons), Emxl-cre (glutamatergic pyramidal neurons of the cortex and hippocampus), and CAG-CreER (tamoxifen-inducible global deletion), we first confirmed that the protein levels and immunohistochemical distribution of $\alpha$ CaMKII was consistent with the expected pattern of deletion as previously reported using other floxed lines. The conditional mutants were further compared with WT and global KO mice. As 
A

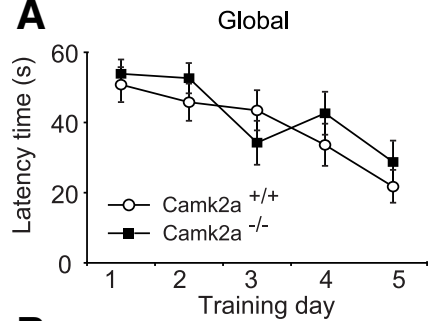

B
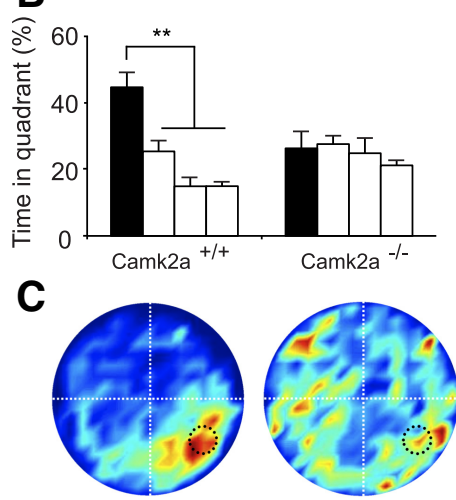

Camk2a ${ }^{+/+}$

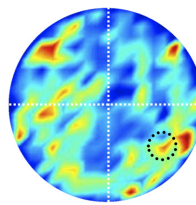

Camk2a $^{-/-}$
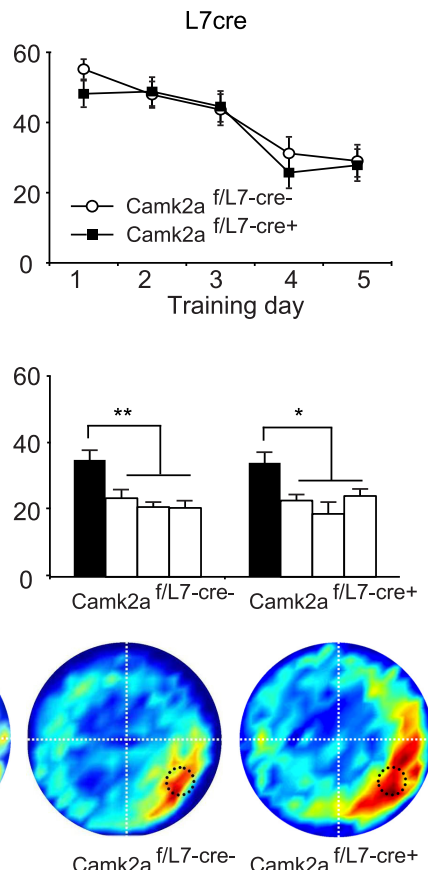

Camk2a ${ }^{\text {f/L7-cre+ }}$
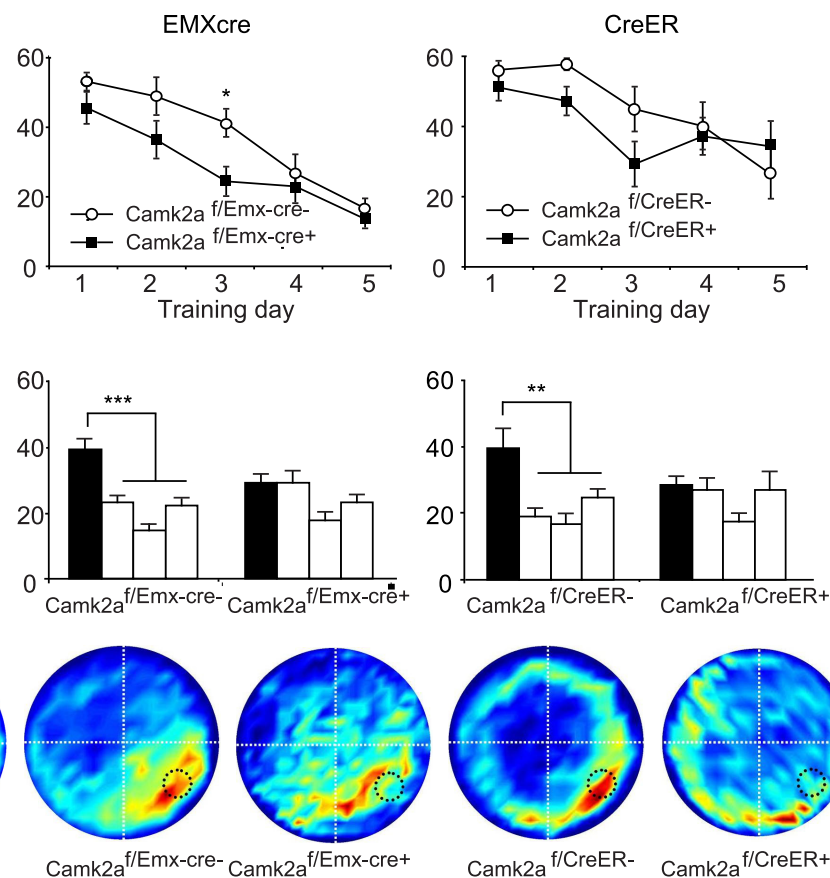

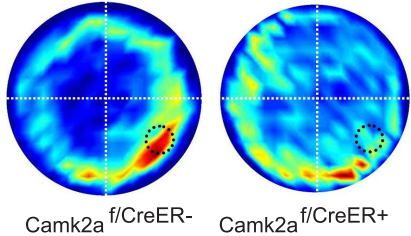

Figure 2. Water maze learning is normal in the absence of cerebellar $\alpha$ CaMKII. $\boldsymbol{A}$, Latency times to reach the hidden platform during training are not different between the Camk2a mutants and their control littermates. $\boldsymbol{B}$, Quantification of the time spent in each quadrant at a probe trial given after $5 \mathrm{~d}$ of training. Black bar indicates the target quadrant; white bars indicate adjacent right, opposite, and adjacent left quadrants, respectively. Error bars represent SEM. Camk $2 a^{+/+}$mice show a clear preference for the platform quadrant, but not Camk $2 a^{-1-}$ mice (left). Camk2a $a^{\text {flox/L7-cre }+}$ mice show a clear preference for the platform quadrant (second panel), whereas (amk2a flox/Emx-cre+ mice (third panel) and Camk2 $a^{\text {flox/CreER+ }}$ mice (last panel) search equally in all four quadrants. All cre-negative control littermates show a clear preference for the platform quadrant. $C$, Visual representation of all swimming tracks of each group of mice combined from the probe trial given at day 5 . The color indicates the time spent at a certain location (red is high, blue is low). Note that Camk2a $a^{-1-}$, Camk2a flox/Emx-cre+ , and Camk2 $a^{\text {flox/CreER+ }}$ mice mice search randomly, whereas the other groups search preferentially around the platform location. The numbers of

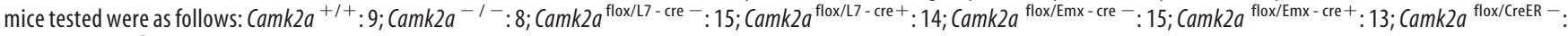
9; and Camk2a flox/CreER+: 10 .

expected, Camk $2 a^{\text {flox/L7-cre }+}$ mice showed a selective loss of $\alpha$ CaMKII expression in cerebellar Purkinje neurons, the only cell type in the cerebellum that normally expresses $\alpha$ CaMKII (Walaas et al., 1988; Fig. $1 B, C)$. In Camk $2 a^{\text {flox/Emx-cre+ }}$ mice, $\alpha$ CaMKII was deleted from cortex and hippocampus, but without any changes in the cerebellum. Consistent with previous reports (Iwasato et al., 2004), recombination was variable across distinct amygdala nuclei. Specifically, high levels of recombination were observed in the basolateral amygdala relative to the lateral amygdala and posterodorsal medial amygdala nucleus. Also consistent with previous findings (Iwasato et al., 2004), we observed a very low residual staining of $\alpha$ CaMKII throughout the telencephalon, with a randomly scattered and sparse distribution of labeled neurons. In contrast, we observed complete tamoxifeninducible deletion of $\alpha \mathrm{CaMKII}$ in adult Camk $2 a^{\text {flox/CreER }+}$ mice. Importantly, however, $\operatorname{Camk} 2 a^{\text {flox }}$ mice lacking cre recombinase had no detectable alteration in their $\alpha$ CaMKII protein levels, confirming that the integrated loxP sites were not interfering with Camk2a gene expression (Fig. $1 B, C$ ).

\section{Telencephalic, but not cerebellar, $\alpha$ CaMKII is required for spatial learning}

Using the hidden version of the Morris water maze, previous studies have demonstrated that $\operatorname{Camk} 2 a^{-1-}$ mice are severely impaired in spatial learning (Silva et al., 1992a; Elgersma et al., 2002). However, the temporal and region-specific requirements for endogenous $\alpha$ CaMKII in spatial learning have not been determined previously. Therefore, we examined the impact of temporal and region-specific deletion of $\alpha$ CaMKII on water maze learning using a $5 \mathrm{~d}$ ( 2 trials/d) training protocol previously shown to result in severe impairments in Camk2a $a^{-1-}$ global knock-out mice in which the same exon was already deleted in germline (Elgersma et al., 2002). In both groups, latency times decreased equivalently (effect of genotype: $F_{(1,15)}=0.46, p=$ 0.51, repeated-measures ANOVA; Fig. $2 A$, first panel). However, consistent with previous studies, we confirmed that $\operatorname{Camk} 2 a^{-1-}$ mice have a severe spatial learning deficit, reflected in no significant preference for the target quadrant compared with the other quadrants $\left(t_{(7)}=2.62, p=0.80\right.$ dependent samples $t$ test; Fig. $2 B$, first panel), whereas Camk2a $a^{+/+}$mice clearly showed a significant preference for the target quadrant $\left(t_{(8)}=4.411, p=0.002\right.$, dependent samples $t$ test; Fig. $2 B$, first panel).

Previous studies have suggested that the cerebellum may contribute significantly to the acquisition of spatial learning (Lalonde and Strazielle, 2003; Burguière et al., 2005; Goddyn et al., 2006; but see also Galliano et al., 2013). Therefore, to examine the specific contribution of cerebellar $\alpha$ CaMKII on spatial learning in our water maze learning paradigm, we tested $\operatorname{Camk} 2 a^{\text {flox/L7 - cre+ }}$ mice and their Camk2 $a^{\text {flox/L7 - cre - }}$ control littermates on the hidden version of the Morris water maze. During training, latency times decreased equivalently in both genotypes (effect of genotype: $F_{(1,27)}=0.408, p=0.53$, repeated-measures ANOVA; Fig. $2 A$, second panel). Moreover, Camk $2 a^{\text {flox/L7 - cre+ }}$ mice were indistinguishable from their littermates in their capacity to locate the platform during the probe trial (average time in platform quadrant, Camk $2 a^{\text {flox } / \mathrm{L} 7-\mathrm{cre}+}: t_{(13)}=2.868, p=0.01$, paired $t$ test; Camk2 $a^{\text {flox } / \mathrm{L} 7-\text { cre }^{-}}: t_{(14)}=3.567, p=0.003$, paired $t$ test; Fig. $2 B$, second panel). Therefore, cerebellar expression of $\alpha$ CaMKII does 
not appear to be required for spatial learning given that Camk2 $a^{\text {flox/L7 - cre }+}$ mice have complete deletion of $\alpha$ CaMKII in the cerebellum yet acquire spatial learning normally under conditions in which global Camk $2 a^{-1-}$ mice are severely impaired.

We next examined the necessity for telencephalic $\alpha$ CaMKII during spatial learning using Camk $2 a^{\text {flox/Emx-cre+ }}$ mice and their

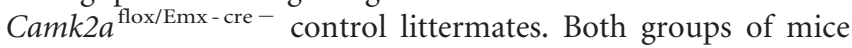
showed an overall similar reduction in their latency times across the training days (Fig. $2 A$, third panel). Although a repeatedmeasures ANOVA showed a significant difference between the groups (effect of genotype: $F_{(1,26)}=6.023, p=0.02$ ), post hoc Tukey's tests showed that a significant difference between the 2 groups was restricted to day $3\left(t_{(26)}=3.171, p=0.004\right)$ and no differences were observed in the initial or final training days. Moreover, consistent with the requirement of telencephalic $\alpha$ CaMKII for spatial learning, $\operatorname{Cam} k 2 a^{\text {flox/Emx -cre }{ }^{+}}$mice showed no significant preference for the target quadrant during the probe $\operatorname{trial}\left(t_{(12)}=1.816, p=0.09\right.$, paired $t$ test; Fig. $2 B$, third panel $)$. In contrast, the Camk $2 a^{\text {flox/Emx-cre - littermates demonstrated ro- }}$ bust spatial learning of the hidden platform location $\left(t_{(14)}=\right.$ $4.656, p=0.0004$, paired $t$ test; Fig. $2 B$, third panel). There was no significant difference in thigmotaxis $\left(t_{(26)}=0.107, p=0.79\right.$, unpaired $t$ test), swim speed $\left(t_{(26)}=1.882, p=0.25\right.$, unpaired $t$ test), or path length $\left(t_{(26)}=1.904, p=0.26\right.$, unpaired $t$ test $)$ between the two groups. Together, our results suggest that, under these commonly used experimental conditions, spatial learning is strongly dependent on $\alpha$ CaMKII expression in the telencephalon, but not the cerebellum.

In addition to its region-specific requirements, we also considered how developmentally regulated expression of $\alpha$ CaMKII influences spatial learning. $\alpha$ CaMKII has been well demonstrated to function critically during NMDA-dependent LTP in the telencephalon, which is widely believed to be an indispensable form of plasticity underlying spatial learning. However, given that $\alpha$ CaMKII expression begins in the early postnatal period, the learning impairments observed in global Camk2a $a^{-1-}$ mice might result from the absence of $\alpha$ CaMKII during early postnatal development, rather than being required specifically at the time of learning. Therefore, we used the tamoxifen-inducible Camk $2 a^{\text {flox/CreER }+}$ mice and their Camk $2 a^{\text {flox/CreER - }}$ littermates to achieve temporal control over the timing of $\alpha$ CaMKII deletion. In particular, we reasoned that, by inducing deletion only in adulthood, we could more directly examine the necessity for $\alpha$ CaMKII specifically at the time of learning while controlling for any potentially confounding abnormalities that might arise from the absence of $\alpha$ CaMKII during early development. Therefore, adult Camk $2 a^{\text {flox/CreER+ }}$ mice and their Camk $2 a^{\text {flox/CreER - }}$ control littermates were given daily injections of tamoxifen $(0.1$ $\mathrm{mg} / \mathrm{g}$, i.p.) for $4 \mathrm{~d}$ to induce gene deletion. As shown in Figure 1, $B$ and $C$, tamoxifen-inducible deletion of $\alpha$ CaMKII in adulthood of Camk2a $a^{\text {flox/CreER+ }}$ mice was highly efficient and without any observed deletion in the absence of tamoxifen, thereby maintaining the full integrity of postnatal development.

During the training phase, Camk $2 a^{\text {flox/CreER }+}$ mice and their Camk $2 a^{\text {flox/CreER - }}$ littermates demonstrated a similar reduction in latency times (effect of genotype: $F_{(1,17)}=1.982, p=0.18$, repeated-measures ANOVA; Fig. $2 A$, last panel). However, during the probe trial, Camk $2 a^{\text {flox/CreER }+}$ mice showed no significant preference for the target quadrant $\left(_{(9)}=1.593, p=0.15\right.$, paired $t$ test; Fig. $2 B$, last panel), whereas their Camk $2 a^{\text {flox/CreER }}$ - littermates demonstrated a search pattern that was highly localized to the location of the hidden platform $\left(t_{(8)}=2.511, p=0.04\right.$, paired $t$ test; Fig. 2B, last panel). There was no significant difference in
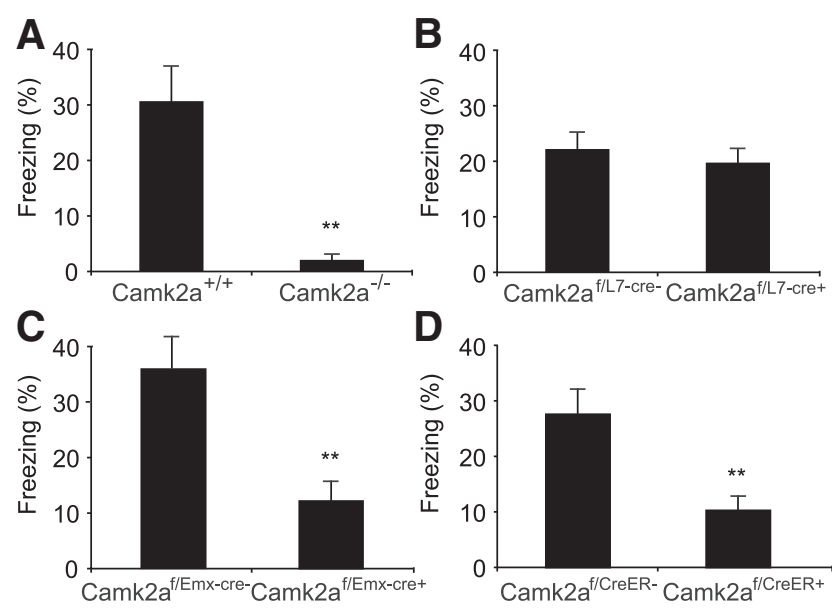

Figure 3. Contextual fear learning is unaffected in the absence of cerebellar $\alpha$ CaMKII. $\boldsymbol{A}$, Compared with Camk2a $a^{+1+}$ mice, Camk2a $a^{-1-}$ mice show no contextual fear learning. $\boldsymbol{B}$, Camk2a flox/L7- ar + mice show intact contextual fear learning compared with their Camk2a flox/L7-cre control littermates. In contrast, Camk2 $a^{\text {flox/Emx-cre+ }}$ mice (C) and Camk2 $a^{\text {flox/CreER+ }}(\boldsymbol{D})$ mice show severe contextual fear learning deficits compared with their Cre-negative control littermates. Num-

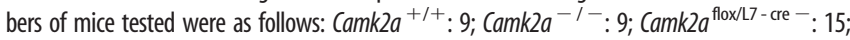

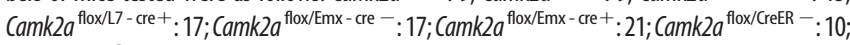
and Camk2 $a^{\text {flox/CreER }+}: 11$. Bars represent the amount of freezing behavior, which is used as an index for recollection of the context. Error bars represent SEM.

thigmotaxis $\left(t_{(17)}=-0.538, p=0.09\right.$, unpaired $t$ test $)$, swim speed $\left(t_{(17)}=0.409, p=0.59\right.$, unpaired $t$ test $)$, or path length $\left(t_{(17)}=-0.140, p=0.95\right.$, unpaired $t$ test $)$ between the two groups. Therefore, $\alpha$ CaMKII is specifically required in adulthood at the time of learning for intact acquisition of spatial information independently of its function during early postnatal development.

\section{Regional and temporally controlled deletion of $\alpha$ CaMKII on contextual fear learning}

Contextual fear conditioning is a highly robust form of associative learning in which unsignaled aversive stimuli (e.g., foot shock) are administered within a previously neutral context in which a range of defensive behaviors (e.g., freezing) are subsequently elicited (Phillips and LeDoux, 1992, 1994). In addition to impaired spatial learning, Camk2 $2^{-1-}$ mice also have been shown to have deficits in contextual conditioning (Silva et al., 1992a). Therefore, we sought to examine the temporal and regionspecific requirements for $\alpha$ CaMKII expression during contextual fear learning.

Consistent with previous studies, we found that Camk $2 a^{-1-}$ mice with a germline deletion of $\alpha$ CaMKII were severely impaired in contextual fear conditioning $\left(t_{(16)}=4.454, p=0.0004\right.$, unpaired $t$ test; Fig. $3 A$ ) compared with their Camk2a $a^{+/+}$littermates. In contrast, Camk $2 a^{\text {flox/L7-cre }+}$ mice with cerebellumspecific deletion of $\alpha$ CaMKII showed similar contextual fear learning as their Camk2 $a^{\text {flox/L7-cre- }}$ control littermates $\left(t_{(30)}=\right.$ $0.621, p=0.57$, unpaired $t$ test; Fig. $3 B$ ), suggesting that Purkinje cell expression of $\alpha \mathrm{CaMKII}$ is not required for normal contextual fear conditioning.

Many previous studies have suggested that contextual fear learning requires NMDA-dependent LTP in the cortex and hippocampus (Levenson et al., 2002; Kiyama et al., 1998). However, no previous studies have examined the telencephalic regionspecific requirement for $\alpha$ CaMKII, despite its being among the most widely hypothesized proteins underlying LTP and learning (for review, see Coultrap and Bayer, 2012). Therefore, using 
A
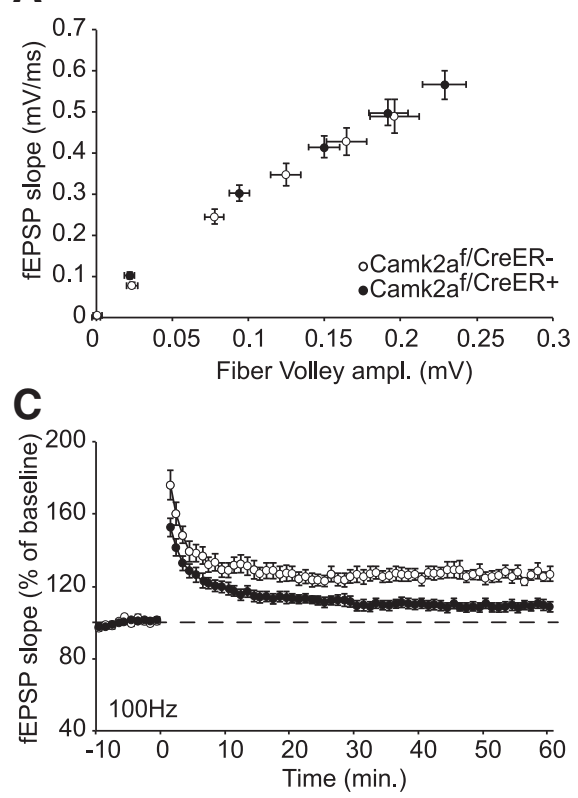

B

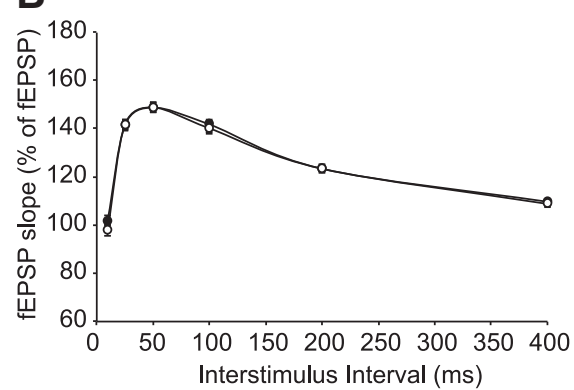

D

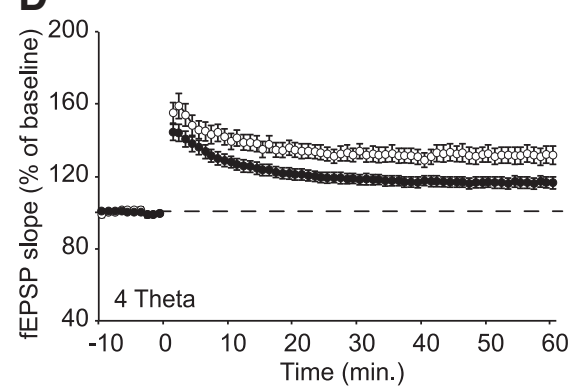

Figure 4. CA3-CA1 LTP is impaired upon deletion of $\alpha$ CaMKII in adulthood. $\boldsymbol{A}$, Camk2a $a^{\text {flox/CreER+ }}$ mice show normal basal synaptic transmission (Camk2a flox/CreER+ $n=37, n=55$; Camk2a $a^{\text {flox/CreER - }} n=39, n=55$ for the number of slices showing fiber volley and fEPSP, respectively). $\boldsymbol{B}$, Camk $2 a^{\text {flox/CreER }+}$ mice show normal PPF ( $n=30$ and $n=31$ for Camk $2 a^{\text {flox/CreER }+}$ and Camk2 $a^{\text {flox/CreER - }}$ mice, respectively). C, Camk2a $a^{\text {flox/CreER+ }}$ mice show impaired $100 \mathrm{~Hz}$ LTP at the CA3-CA1 synapse in the

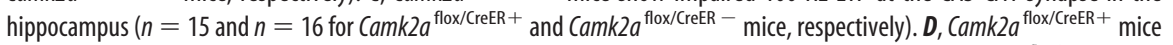
show impaired 4 Theta LTP at the CA3-CA1 synapse in the hippocampus ( $n=31$ and $n=23$ for Camk2a flox/CreER+ and Camk2a $a^{\text {flox/CreER }-}$ mice, respectively). Error bars indicate SEM.

Camk $2 a^{\text {flox/Emx - cre+ }}$ mice, we investigated whether the expression of $\alpha$ CaMKII specifically in the telencephalon was required for contextual conditioning. Indeed, as predicted by the predominant models of synaptic plasticity and learning, Camk $2 a^{\text {flox/Emx- }}$ cre + mice showed a significant impairment in contextual fear learning compared with their littermate controls $\left(t_{(36)}=3.773, p=\right.$ 0.001; unpaired $t$ test; Fig. $3 C$ ).

In addition to the region-specific requirements for $\alpha$ CaMKII, we also examined the temporal requirement during contextual fear learning. In particular, we sought to determine whether the conditioning deficit in the global Camk $2 a^{-1-}$ mice arises from a developmental abnormality or if it is due to the absence of $\alpha$ CaMKII in adulthood at the time of learning. Therefore, we again used Camk $2 a^{\text {flox/CreER+ }}$ mice to induce $\alpha$ CaMKII deletion selectively in adulthood while sparing the potential impact of deletion during early development. Consistent with a requirement for $\alpha$ CaMKII expression at the time of learning, Camk $2 a^{\text {flox/CreER+ }}$ mice with temporally restricted adult deletion showed a severe impairment of contextual learning $\left(t_{(19)}=4.950, p=0.0001\right.$, unpaired $t$ test; Fig. $3 D)$.

\section{LTP is impaired in mice with adult deletion of $\alpha$ CaMKII}

In addition to deficits in the Morris water maze and contextual fear conditioning, Camk2a $a^{-1-}$ mice also show an impairment in LTP thought to underlie these hippocampal-dependent forms of learning (Silva et al., 1992b; Elgersma et al., 2002). Therefore, given the spatial and contextual learning deficits in Camk $2 a^{\text {flox/CreER+ }}$ mice, we also performed field recordings in acute hippocampal slices to determine whether adult-restricted deletion also impaired synaptic plasticity. Efficacy of synaptic transmission was unaffected in the absence of $\alpha$ CaMKII (Fig. $4 A$ ). Fiber volley amplitude was not significantly different in Camk $2 a^{\text {flox/CreER }+}$ mice compared with their control littermates (effect of genotype: $F_{(1,74)}=2.37, p=0.13$, repeatedmeasures ANOVA; Fig. 4A). Postsynaptic fEPSP slope was also independent of $\alpha$ CaMKII, which is consistent with previous studies using Camk2a-1- mice (effect of genotype: $F_{(1,108)}=2.97, p=0.09$, repeated-measures ANOVA; Fig. 4A). Moreover, PPF was also unchanged in Camk $2 a^{\text {flox/CreER }+}$ mice (effect of genotype: $F_{(1,59)}=0.26, p=0.61$, repeated-measures ANOVA; Fig. $4 B$ ).

To determine whether the LTP impairment observed in Camk $2 a^{-1-}$ mice is due to a critical role for $\alpha$ CaMKII during development and/or whether $\alpha$ CaMKII is necessary for the induction of LTP in adulthood, we used two independent protocols to induce LTP $(100 \mathrm{~Hz}$ and thetaburst protocols) given their distinct cellular mechanisms yet shared impairment in Camk2a $a^{-1-}$ mice. Both stimulation protocols induced robust LTP in control littermates (Camk2a $a^{\text {flox/CreER - }}$; Fig. $4 C, D)$. However, Camk2a flox/CreER+ mice with adult-specific deletion of $\alpha$ CaMKII showed impaired LTP in both the $100 \mathrm{~Hz}$ (effect of genotype: $F_{(1,29)}=$ 16.88, $p=0.0003$, repeated-measures ANOVA; Fig. $4 C$ ) and theta-burst protocol (effect of genotype: $F_{(1,52)}=7.85, p=$ 0.007, repeated-measures ANOVA; Fig. 4D). Together, these findings confirm that $\alpha \mathrm{CaMKII}$ is specifically required in adulthood for both learning and synaptic plasticity.

\section{Discussion}

In the present study, we used conditional Camk2a mutant mice to determine the influence of spatially restricted and temporally controlled deletion of $\alpha$ CaMKII. The present series of experiments demonstrate that $\alpha$ CaMKII is required during adulthood in the telencephalon, but not the cerebellum, for both spatial and contextual learning and hippocampal LTP. Importantly, these results are entirely consistent with previous research showing that global germline deletion of $\alpha$ CaMKII leads to deficits in hippocampal-dependent learning and LTP (Silva et al., 1992a; Silva et al., 1992b; Elgersma et al., 2004). However, no previous experiments had ever been able to control for the possibility that germline deletion of $\alpha \mathrm{CaMKII}$ might have led to abnormalities in early brain development, rather than its requirement in adulthood at the time of learning. Moreover, given evidence in the literature regarding the influence of cerebellar Purkinje cell plasticity in spatial and contextual learning (Lalonde and Strazielle, 2003; Burguière et al., 2005; Goddyn et al., 2006), we also examined region-specific Camk2a deletion.

Previous studies using inducible systems (Mayford et al., 1996; Wang et al., 2003) investigated the necessity of $\alpha$ CaMKII during plasticity and learning using overexpression of a mutated temporally controlled and region-specific Camk2a transgene. Although these studies show that enhanced levels of $\alpha$ CaMKII in the forebrain, independently of its activity status, can interfere with learning and memory consolidation, they do not prove the requirement of endogenous $\alpha$ CaMKII for plasticity and learning. Temporal overexpression of the $\alpha$ CaMKII-T286D transgene, 
which is thought to have a dominant-negative effect due to additional phosphorylation on the TT305/6 sites (Pi et al., 2010), caused changes in the frequency threshold for LTP induction and disruption of several learning paradigms, which is reversed when turning off the transgene (Mayford et al., 1996). These experiments indicate a critical role for CaMKII signaling during learning. However, because $\alpha$ CaMKII forms holoenzymes with $\beta$ CaMKII, these studies do not rule out that the phenotype is caused by deregulation of the entire holoenzyme (rather than just $\alpha$ CaMKII) due to the dominant-negative effect of the $\alpha$ CaMKIIT286D protein (Pi et al., 2010). Indeed, the dominant-negative mutation $\alpha$ CaMKII-T305D results in a much stronger deficit than Camk2a $a^{-1-}$ mice (Elgersma et al., 2002).

Temporal overexpression of $\alpha$ CaMKII-F89G (of which the activity can be regulated by specific inhibitors) in adult mice showed that increased CaMKII expression during training and the next 4 weeks had no effects on long-term contextual and cued-fear memories as long as this level was not changed during consolidation or upon recall (Wang et al., 2003). Therefore, these studies indicated that a constant level of CaMKII during the phases of acquisition, consolidation, or recall was critical for normal learning, but did not address the requirement for endogenous $\alpha$ CaMKII for learning. In contrast, administering tatCN21 (a fusion peptide that inhibits stimulated and autonomous CaMKII activity) did not impair contextual fear memory expression when given $1 \mathrm{~h}$ before testing (Buard et al., 2010). Importantly, however, when tatCN21 was administered $1 \mathrm{~h}$ before training, acquisition was significantly impaired, confirming the necessity of CaMKII for intact learning and in full agreement with our findings.

Notably, we observed that mice with deletion restricted to the cerebellum demonstrated normal spatial and contextual learning, consistent with a recent study examining multiple lines of mice, each with distinct impairments in cerebellar transmission and plasticity, which found no evidence of cognitive impairments, including spatial and contextual learning (Galliano et al., 2013). Future studies should be aimed at further dissecting the regional and cell-type specific contributions of $\alpha$ CaMKII during learning, including the hippocampal subfields and amygdala nuclei. Moreover, it will also be important to explore the differential contributions of $\alpha$ CaMKII during the various phases of memory, including acquisition, consolidation, reconsolidation, maintenance, and retrieval.

We have confirmed that the well characterized learning deficits in Camk2a $a^{-1-}$ mice are not merely due to absence of the protein during the developmental period. In the present study, mice with temporally restricted deletion of $\alpha$ CaMKII in adulthood showed equivalent spatial and contextual learning deficits as observed in the global Camk2a-1- mutants that lack $\alpha$ CaMKII expression throughout postnatal development. Therefore, we conclude that temporally controlled deletion of Camk2a in adult mice is as detrimental as germline deletion for spatial and contextual learning.

\section{References}

Anagnostaras SG, Wood SC, Shuman T, Cai DJ, Leduc AD, Zurn KR, Zurn JB, Sage JR, Herrera GM (2010) Automated assessment of Pavlovian conditioned freezing and shock reactivity in mice using the video freeze system. Front Behav Neurosci 4:pii:158. CrossRef Medline

Barski JJ, Dethleffsen K, Meyer M (2000) Cre recombinase expression in cerebellar Purkinje cells. Genesis 28:93-98. CrossRef Medline

Benson DL, Isackson PJ, Gall CM, Jones EG (1992) Contrasting patterns in the localization of glutamic acid decarboxylase and $\mathrm{Ca}^{2+} /$ calmodulin protein kinase gene expression in the rat central nervous system. Neuroscience 46:825-849. CrossRef Medline

Buard I, Coultrap SJ, Freund RK, Lee YS, Dell'Acqua ML, Silva AJ, Bayer KU (2010) CaMKII "autonomy" is required for initiating but not for maintaining neuronal long-term information storage. J Neurosci 30:82148220. CrossRef Medline

Burguière E, Arleo A, Hojjati MR, Elgersma Y, De Zeeuw CI, Berthoz A, Rondi-Reig L (2005) Spatial navigation impairment in mice lacking cerebellar LTD: a motor adaptation deficit? Nat Neurosci 8:1292-1294. CrossRef Medline

Burguière E, Arabo A, Jarlier F, De Zeeuw CI, Rondi-Reig L (2010) Role of the cerebellar cortex in conditioned goal-directed behavior. J Neurosci 30:13265-13271. CrossRef Medline

Coultrap SJ, Bayer KU (2012) CaMKII regulation in information processing and storage. Trends Neurosci 35:607-618. CrossRef Medline

Elgersma Y, Fedorov NB, Ikonen S, Choi ES, Elgersma M, Carvalho OM, Giese KP, Silva AJ (2002) Inhibitory autophosphorylation of CaMKII controls PSD association, plasticity, and learning. Neuron 36:493-505. CrossRef Medline

Elgersma Y, Sweatt JD, Giese KP (2004) Mouse genetic approaches to investigating calcium/calmodulin-dependent protein kinase II function in plasticity and cognition. J Neurosci 24:8410-8415. CrossRef Medline

Galliano E, Potters JW, Elgersma Y, Wisden W, Kushner SA, De Zeeuw CI, Hoebeek FE (2013) Synaptic transmission and plasticity at inputs to murine cerebellar Purkinje cells are largely dispensable for standard nonmotor tasks. J Neurosci 33:12599-12618. CrossRef Medline

Giese KP, Fedorov NB, Filipkowski RK, Silva AJ (1998) Autophosphorylation at Thr286 of the alpha calcium-calmodulin kinase II in LTP and learning. Science 279:870-873. CrossRef Medline

Goddyn H, Leo S, Meert T, D’Hooge R (2006) Differences in behavioural test battery performance between mice with hippocampal and cerebellar lesions. Behav Brain Res 173:138-147. CrossRef Medline

Hansel C, de Jeu M, Belmeguenai A, Houtman SH, Buitendijk GH, Andreev D, De Zeeuw CI, Elgersma Y (2006) alphaCaMKII Is essential for cerebellar LTD and motor learning. Neuron 51:835-843. CrossRef Medline

Hayashi S, McMahon AP (2002) Efficient recombination in diverse tissues by a tamoxifen-inducible form of Cre: a tool for temporally regulated gene activation/inactivation in the mouse. Dev Biol 244:305-318. CrossRef Medline

Iwasato T, Nomura R, Ando R, Ikeda T, Tanaka M, Itohara S (2004) Dorsal telencephalon-specific expression of Cre recombinase in PAC transgenic mice. Genesis 38:130-138. CrossRef Medline

Jones EG, Huntley GW, Benson DL (1994) Alpha calcium/calmodulindependent protein-kinase II selectively expressed in a subpopulation of excitatory neurons in monkey sensory-motor cortex-comparison with Gad-67 expression. J Neurosci 14:611-629. Medline

Kiyama Y, Manabe T, Sakimura K, Kawakami F, Mori H, Mishina M (1998) Increased thresholds for long-term potentiation and contextual learning in mice lacking the NMDA-type glutamate receptor epsilon 1 subunit. J Neurosci 18:6704-6712. Medline

Lalonde R, Strazielle C (2003) The effects of cerebellar damage on maze learning in animals. Cerebellum 2:300-309. CrossRef Medline

Levenson J, Weeber E, Selcher JC, Kategaya LS, Sweatt JD, Eskin A (2002) Long-term potentiation and contextual fear conditioning increase neuronal glutamate uptake. Nat Neurosci 5:155-161. CrossRef Medline

Mayford M, Bach ME, Huang YY, Wang L, Hawkins RD, Kandel ER (1996) Control of memory formation through regulated expression of a CaMKII transgene. Science 274:1678-1683. CrossRef Medline

Oberdick J, Smeyne RJ, Mann JR, Zackson S, Morgan JI (1990) A promoter that drives transgene expression in cerebellar Purkinje and retinal bipolar neurons. Science 248:223-226. CrossRef Medline

Phillips RG, LeDoux JE (1992) Differential contribution of amygdala and hippocampus to cued and contextual fear conditioning. Behav Neurosci 106:274-285. CrossRef Medline

Phillips RG, LeDoux JE (1994) Lesions of the dorsal hippocampalformation interfere with background but not foreground contextual fear conditioning. Learn Mem 1:34-44. CrossRef Medline

Pi HJ, Otmakhov N, Lemelin D, De Koninck P, Lisman J (2010) Autono- 
mous CaMKII can promote either long-term potentiation or long-term depression, depending on the state of T305/T306 phosphorylation. J Neurosci 30:8704-8709. CrossRef Medline

Sik A, Hájos N, Gulácsi A, Mody I, Freund TF (1998) The absence of a major $\mathrm{Ca}^{2+}$ signaling pathway in GABAergic neurons of the hippocampus. Proc Natl Acad Sci U S A 95:3245-3250. CrossRef Medline

Silva AJ, Paylor R, Wehner JM, Tonegawa S (1992a) Impaired spatial learning in alpha-calcium-calmodulin kinase II mutant mice. Science 257: 206-211. CrossRef Medline

Silva AJ, Stevens CF, Tonegawa S, Wang Y (1992b) Deficient hippocampal long-term potentiation in alpha-calcium-calmodulin kinase II mutant mice. Science 257:201-206. CrossRef Medline

Simeone A, Gulisano M, Acampora D, Stornaiuolo A, Rambaldi M, Boncinelli E (1992) Two vertebrate homeobox genes related to the Drosophila empty spiracles gene are expressed in the embryonic cerebral cortex. EMBO J 11:2541-2550. Medline

Smeyne RJ, Oberdick J, Schilling K, Berrebi AS, Mugnaini E, Morgan JI (1991) Dynamic organization of developing Purkinje cells revealed by transgene expression. Science 254:719-721. CrossRef Medline
Takeuchi Y, Fukunaga K, Miyamoto E (2002) Activation of nuclear $\mathrm{Ca}(2+) /$ calmodulin-dependent protein kinase II and brain-derived neurotrophic factor gene expression by stimulation of dopamine $\mathrm{D} 2$ receptor in transfected NG108-15 cells. J Neurochem 82:316-328. CrossRef Medline

Van Duyne GD (2001) A structural view of Cre-loxP site-specific recombination. Annu Rev Biophys Biomol Struct 30:87-104. CrossRef Medline

Vogt MA, Chourbaji S, Brandwein C, Dormann C, Sprengel R, Gass P (2008) Suitability of tamoxifen-induced mutagenesis for behavioral phenotyping. Exp Neurol 211:25-33. CrossRef Medline

Walaas SI, Lai Y, Gorelick FS, DeCamilli P, Moretti M, Greengard P (1988) Cell-specific localization of the alpha-subunit of calcium/calmodulindependent protein kinase II in Purkinje cells in rodent cerebellum. Brain Res 464:233-242. Medline

Wang H, Shimizu E, Tang YP, Cho M, Kyin M, Zuo W, Robinson DA, Alaimo PJ, Zhang C, Morimoto H, Zhuo M, Feng R, Shokat KM, Tsien JZ (2003) Inducible protein knock-out reveals temporal requirement of CaMKII reactivation for memory consolidation in the brain. Proc Natl Acad Sci U S A 100:4287-4292. CrossRef Medline 